American Journal of Economics and Business Administration 4 (1): 13-22, 2012

ISSN 1945-5488

(C) 2012 Science Publications

\title{
Learning from Lessons Learned: Project Management Research Program
}

\author{
Kam Jugdev \\ Department of Economics, Finance and Operations Management, \\ Faculty of Business, Athabasca University, T8N 1B4 301, \\ 22 Sir Winston Churchill Avenue, St. Albert, Alberta, Canada
}

\begin{abstract}
Problem statement: When we fail to learn from our own mistakes or those of others, we tend to repeat the mistakes. This study discusses lessons learned as important ways of gathering and sharing both formal and informal project knowledge. Approach: The study presents findings of three studies from a research program on lessons learned. The first study is a content analysis of two sets of conference proceedings. The second study is a case study from the energy sector on lessons learned. The final study is a content analysis of the Project Management Body of Knowledge ${ }^{\circledR}$ Guide. Results: The conference proceedings study indicated that the topic of lessons learned was under represented within the conference proceedings. This was in keeping with the literature review that the topic of lessons learned is emerging. The energy sector study shed light on the lessons learned process, best practices and challenges. The content analysis of the Project Management Body of Knowledge Guide ${ }^{\circledR}$ showed that the guide defines lessons learned narrowly, primarily as a set of administrative, documented outputs pertaining mainly to the closeout phase. This was also evident in the guide's commodification of lessons learned (and related terms). Conclusion/Recommendations: This study contributes to the fields of project management, knowledge management and workplace learning. Academics and practitioners use various terms to refer to lessons learned. Negative events often compel companies to add lessons learned practices to their project management processes. In order to conduct effective lessons learned, there has to be management support, the right stakeholders should be involved and knowledge should be shared in both codified and uncodified ways. Lessons learned are processes that involve formal and informal learning. Effective lessons learned can be embedded into a company's practices, especially through informal learning and sharing practices, such as through Communities of Practice and by applying principles from workplace learning, such as situated learning theory.
\end{abstract}

Key words: Communities of practice, content analysis, knowledge management, project reviews, situated learning theory, workplace learning

\section{INTRODUCTION}

Projects are complex undertakings and involve a myriad of challenges. These challenges include aggressive local and foreign competition, alliances, project performance volatility, contractual issues and staff turnover (Wilczynski et al., 2006). These challenges are critical in and of themselves. The challenges also have implications on how lessons learned are done and the value of lessons learned in terms of their use and reuse.

As an extension of project management, lessons learned are an efficient and effective way of transferring valuable project knowledge-the good, the bad and the ugly. Lessons learned involve sharing knowledge about the elements of specific project phases that went according to plan, the parts that could be improved on and plans to address these issues before moving on to the next phase. We view lessons learned to be broadly defined as involving a variety of activities and processes.
However, lessons learned are often done superficially and resisted. Inevitably, crucial knowledge gained from a project is not always documented or communicated for subsequent use. These factors contribute to increased project costs, extended schedules and a lack of communication, considerable rework and costly mistakes.

The topic of lessons learned is important for several reasons. First, achieving good results at the operational level contributes to an improved bottom line. Second, we know that knowledge-based assets are a source of competitive advantage (Foss, 1996; O'Dell and Grayson, 1998; Teece, 1998). Not only can learning from prior project experiences help achieve economies of learning, but also, such practices can enhance a company's competitive advantage, because knowledge-based practices can be unique, difficult to copy and become organizationally embedded over time. And third, over 80 percent of workplace learning occurs informally versus formally 
(Shani and Docherty, 2003) and lessons learned involve informal and formal practices.

This study contributes to the fields of project management, knowledge management and workplace learning. We begin with a literature review on lessons learned followed by overviews of three studies from this research program on a:

- Content analysis of multiple conference proceedings

- Qualitative study based in the energy sector

- Content analysis of the Project Management Institute's (PMI ${ }^{\circledR}$ ) Project Management Body of Knowledge Guide (PMBOK ${ }^{\circledR}$ Guide)

The aims of this study are to present a snapshot of the literature on lessons learned, how lessons learned are used in industry and the narrow ways in which they are presented in the literature and PMBOK $^{\circledR}$ Guide. In doing so the purpose is to advance the views that lessons learned are more than administrative and documented project activities. Lessons learned are processes that involve formal and informal workplace learning and tacit knowledge sharing. We conclude the study with recommendations for theory, research and practice.

Literature review: Project management is an experiential (applied discipline). Project management involves a variety of structured and unstructured processes and practices, including ways in which project participants learn on and from projects. Two well-known ways of gathering, transforming and sharing project learning's include the more structured project lessons learned (project reviews) and the often less structured Community of Practice $(\mathrm{CoP})$.

PMI's PMBOK ${ }^{\circledR}$ Guide defines lessons learned as "the learning gained from the process of performing the project. Lessons learned may be identified at any point. Also considered a project record, to be included in the lessons learned knowledge base" (PMI, 2010). This definition emphasizes that experience is central to lessons learned and that lessons learned can occur at any point of the project lifecycle, even though most such exercises are conducted at the closeout phase. Defined narrowly, lessons learned then, are one set of important project outputs delivered at the end of the project. Defined more broadly, lessons learned are the learning (in its various forms), that take place throughout a project and between projects.

Management and education literature domains: A review of the literature indicated that the main theoretical domains relevant to lessons learned stem from the fields of strategic management, organizational learning (which includes knowledge management), social capital and workplace learning (Thompson and Jugdev, 2010). Sources of competitive advantage involve knowledge-based resources (Pettigrew et al., 2006) people learn at the individual, group and organizational levels to create, acquire, capture, share and use knowledge (Currie, 2003) knowledge is both explicit and tacit (Nonaka and Takeuchi, 1995) and knowledge is shared socially through connections with others to promote durable networks, trust and cooperation (Prusak and Cohen, 2002). Lessons learned and sharing occurs through formal and informal ways-such as through CoPs. Whereas formal learning typically takes place in an educational setting, workplace learning includes all forms of learning (i.e., formal, informal, selfdirected, collective and tacit) (Bratton et al., 2003).

The scholarly study of learning is evident in the fields of education, organizational and management studies, human resource development and workplace learning. We were drawn to workplace learning because of our interest in examining how project management practitioners learn and share on and from projects in the lessons learned and $\mathrm{CoP}$ contexts (formal and informal learning and sharing) (Thompson and Jugdev, 2010). Similar to the management domains and unlike the project management domain, the workplace learning field is a more established and broadly researched area and it includes practice-based learning theories. Workplace learning encompasses all forms of learning in the workplace including formal, non-formal, self-directed, collective and informal learning activities (Bratton et al., 2003). Within the work-learning field, there is increasing interest in practice-based theories. Situated learning theory is one such perspective used widely within the workplace learning field that focuses on learning in a collective manner, such as through CoPs (Lave and Wenger, 1991). Unlike formal or classroom learning, which tends to be abstract, non-contextual and intentional, situated learning is embedded in the practice, context and culture (Lave and Wenger, 1991). For the purposes of this study, we use the broader term, workplace learning.

We follow Fenwick's understanding of learning in work. Fenwick states that such learning is practicebased, participative and may involve formal or informal teaching (Fenwick, 2008). Learning is also "embedded in action, not centered in an individual's head but distributed among activities and continuous interactions and relationships of people within a system" (p. 228). Lave indicates that both transmission and transfer are problematic terms when used to describe the circulation of knowledge. Knowledge is not like a ball, which can be passed from one person to the next while maintaining a consistent shape. Instead, it changes as it circulates. Although CoP often embodies informal learning strategies, it cannot be assumed that the learning processes are necessarily informal. This is particularly important in an organizational context in which a company expects to harvest and formalize the knowledge that is being built and shared in such networks, including lessons learned. 
Project management literature: Projects involve the use of a variety of project management practices and each company brings its own tools, techniques, methodologies and templates to the Table, including lessons learned practices. Outsourcing the project management function can impact the timing and method of conducting lessons learned, the ability to learn from both a company's own mistakes and the mistakes made by other companies involved (Wilczynski et al., 2006). The extent of knowledge sharing on projects is further impacted by the contracting arrangements between the primary stakeholder groups and the dynamics between them. Contract types reflect the risk allocation strategies used and extent of trust and cooperation between the parties, often at the expense of joint performance goals because the risk-reward objectives reflect competing interests. Another challenge relates to training new workers, especially in light of staff turnover and the demographic shifts as more Baby Boomers retire this decade. Although succession planning plays a role in addressing this "brain drain", it may not be the full answer. As a result, lessons learned practices and processes can help address aspects of learning and sharing since not all knowledge can be codified.

As shown in Table 1, commonly used synonyms for lessons learned include project assessments, project reviews, project completion audits, post mortems, reviews, appraisals, after-action reviews, debriefings and post-implementation evaluations (Disterer, 2002). The topic of lessons learned is gaining in importance (Crawford et al., 2006), yet remains in its infancy. The project management literature describes lessons learned as practices that:

- Is quality improvement oriented and help correct process efficiency and effectiveness problems in a timely manner (Schindler, 2003; Kotnour, 1999; Kamara et al., 2002; Koners and Goffin, 2007)

- Help deliver more successful projects, improve customer satisfaction (Kotnour, 1999) and help participants learn about successful and unsuccessful practices (Busby, 1999)

- Involve dissemination and sharing functions (Busby, 1999)

- Involve both inter-and intra-project learnings (Kotnour, 1999) because they assist with externalizing implicit knowledge (Disterer, 2002)

In the literature, barriers to lessons learned were similar to the barriers of effective knowledge management practices. Some commonly cited barriers included company culture, structure, processes (Long et al., 2000) and corporate amnesia/project amnesia (Schindler, 2003; Kransdorff, 1996). At the individual level, staff may not necessarily seek the information and skills they need or they may not have the skills and expertise to conduct lessons learned effectively (Schindler, 2003). Staff may resist learning from the mistakes of others or take the attitude that if it was not invented here it does not apply to us (Egbu, 2004). Some may even perceive of "knowledge as power" (Long et al., 2000) to avoid sharing.

Most of the project management literature portrayed lessons learned as overly simplistic knowledge management and/or quality improvement practices and few referred to the complexities of lessons learned that the learning domains/theories address. The study (Currie, 2003; Kamara et al., 2002; Egbu, 2004; Christensen and Bang, 2003; Liebowitz and Megbolugbe, 2003; Snider and Nissen, 2003) did not base empirical work in knowledge management or organizational learning theories. Instead, the study tended to be descriptive and applied in nature. The study primarily provided anecdotal best practices, prescriptive advice, or discussed results based on action research and/or single case studies. The study also tended to refer to CoPs in passing.

In the project management context, a CoP allows participants to share both tacit and explicit knowledge and create an ongoing culture of informal project knowledge sharing. Embraced to some extent, various companies have formal project management offices through which voluntary brownbag lunch sessions or topic-specific discussions to help develop CoPs may be organized. A limitation of the PMBOK $^{\circledR}$ Guide is that it is deficient in both defining and elaborating on CoPs. Little project management study acknowledged the need to adopt a workplace learning approach to apply to cross-project learning yet this accounts for the socially embedded nature of knowledge and its development within CoPs.

Wenger (1999) described CoPs as structures that enable peer-to-peer learning among practitioners. Although a stream of research exists on CoPs in project management, this body of work also tended to be descriptive (Kamara et al., 2002; Egbu, 2004; Liebowitz and Megbolugbe, 2003; Snider and Nissen, 2003; Gongla and Rizzuto, 2001; Garrety et al., 2004; Lesser and Storck, 2001; Kransdorff and Williams, 1999).

\begin{tabular}{lll} 
Table 1: Commonly used synonyms for lessons learned & & \\
\hline - Lessons learned & - Post-implementation evaluation & - Project debriefing \\
- After-action review & - Post-implementation review & - Project evaluation \\
- Completion audit & - Post mortem & - Project implementation review \\
- Experience factory & - Project appraisal & - Project review \\
- Health check & - Project audit & - Reuse planning \\
\hline
\end{tabular}


The project management field presented a CoP as a tangible construct at the expense of its quite significant intrinsic value that exists in the workplace learning and social learning contexts.

In the project management literature, learning was rarely well defined and few publications articulated their purpose for studying it in the lessons learned or CoP contexts. These assessments were supported by others in the field (Koners and Goffin, 2007; Newell et al., 2006; Williams, 2007; 2008). However, there were several exceptions to this critique, such as the studies by Julian (2008); Newell et al. (2006) and Sense (2003; 2004; 2008).

Project management literature based on workplace learning theories: Several scholars in the project management field acknowledged the need to adopt a situated approach to cross-project learning (Newell et al., 2006; Sense, 2003; 2004; 2008; Julian, 2008).

Julian's study focused on project management office leaders as facilitators of project learning and continuous improvement (Julian, 2008). Julian applied elements of Wenger's framework on CoP to discuss constellations of practice. Project team members belong to multiple $\mathrm{CoPs}$ and participate in knowledge brokering, knowledge encounters and reflective practices (e.g., tacit learning based on content, process and premise whereby people stop and think in order to give meaning to an experience) (Wenger, 1999).

The study by Newell et al. (2006) was on sharing lessons learned knowledge across projects. They contended that lessons learned in and of themselves were not very helpful and that it was necessary to explore the underpinning assumptions about knowledge. They also indicated that the idea of knowledge as a possession was constraining because it only dealt with knowledge that could be made explicit. This view, which ignored the situated nature of knowledge, probably accounted for the lack of success of most cross-project knowledge transfer initiatives that were reported in the literature.

Sense also examined project management within the context of workplace learning and $\mathrm{CoP}$ by drawing extensively on Wenger's situated learning concepts (Sense, 2003; 2004; 2008; Sense and Badham, 2008). He presented the argument that project teams can be "an embryonic form of a CoP" and he referred to them as "learning generators" (Sense, 2003). In this manner, project teams engage in lessons learned both within and between projects. In a subsequent study Sense maintained that the learning architecture for project work was based on the elements of learning relationships, cognitive style, knowledge management, learning mandate and learning environment support and pyramid of authority (Sense, 2008). He further indicated that perceiving the flow of project management knowledge as technical knowledge (which can be codified) was too prevalent and that more focus needed to be placed on the personalization and social approaches to knowledge flows to enhance knowledge creation and sharing practices.

Our premise is that these limitations in the project management field pertain to the discipline not yet intersecting with the field of workplace learning. A contribution of our literature review was to introduce workplace learning theories to the field of project management. Situated learning theory offers a different lens with which to conceptualize and research lessons learned because lessons learned practices involve learning and sharing through socially constructed ways (Sense and Badham, 2008; Hemetsberger and Reinhardt, 2006).

As a further contribution to the field, several studies from our research program are presented next.

\section{Lessons learned research program:}

Study 1: 2006-Content analysis of conference proceedings: Content analysis (or textual analysis) is a form of systematic data analysis that helps count words, interpret themes and examine word patterns (Ahuvia, 2001; Cameron, 2011; Duriau et al., 2007).

\section{MATERIALS AND METHODS}

We began by searching the ABI Inform $^{\circledR}$ database to conduct our literature review on project management lessons learned. This approach enabled us to iteratively identify the following Table 115 terms.

These words were used to analyze two sets of project management conference proceedings for the 1999-2005 timeframe. We analyzed proceedings from the $\mathrm{PMI}^{\circledR}$ and Portland International Centre for Management of Engineering and Technology ${ }^{\circledR}$ conferences because both organizations focus on project management. The analysis sought study that primarily addressed lessons learned. The aim was to examine key word frequencies in the study in a meaningful way.

Using specific rules for content analysis, we reviewed a total of 2,128 studies. 613 of this study were in the PMI ${ }^{\circledR}$ conference proceedings and found to be primarily practitioner-oriented.

\section{RESULTS}

Only 11 study (1.8\%) addressed lessons learned in a significant manner. In contrast, the 1,515 study in the Portland International Centre for Management of Engineering and Technology ${ }^{\circledR}$ proceedings were primarily academic in nature. However, only one study $(0.07 \%)$ addressed lessons learned in a 
significant manner. In the entire analysis, little study drew from the academic literature on lessons learned on organizational learning and knowledge management. No study was situated in the workplace learning domain.

The content analysis indicated that the topic of lessons learned was under represented within the conference proceedings. This was in keeping with the literature review that lessons learned as a topic is emerging in project management (Crawford et al., 2006), but has yet to flourish. The literature review and content analysis led us to conduct an exploratory study on lessons learned.

Study 2: 2006-Qualitative interviews in the energy sector: This exploratory qualitative study focused on how lessons learned were conducted in the oil and gas industry (Jugdev, 2006). The study was based on our literature review. We focused on lessons learned because they involve different forms of learning and sharing and because lessons learned were a construct that practitioners related to. The questions probed historical events, the processes involved and best practices and challenges.

Study 1: Materials and methods: 15 practitioners (11 males and 4 females) were interviewed in three oil and gas companies and two engineering, procurement and construction firms. Participant ages ranged from 31-66 years; $13 / 15$ were engineers; and they had an average of 22 years of work experience. Our findings were drawn from meta-level analyses of the transcripts and conclusions generalized to that sample.

Study 1: Results: Participant definitions of lessons learned were consistent with the literature. "I guess the phrase is we want to be looking forward not in a rear-view mirror. We want to see what's going to hit us rather than just what happened" (LG, p. 6). The six main themes that emerged in the transcript analyses are briefly presented next.

Events precipitating the use of project lessons learned: Participants indicated that their companies had used lessons learned for many years. Their prior project experiences prominently involved formal lessons learned practices. Some described "nightmare" project experiences and the implications to the bottom line. As one participant indicated, "And nobody will understand the lessons learned better than the person who experienced it and had, you know, skin in the game and experienced pain around it or the reward of doing something very well" (DN, p. 7).

The lessons learned process: Typically, project managers, external facilitators, or members of the Project Management Office facilitated lessons learned meetings using standard forms and templates. The meetings were often held at key points, such as milestones, project phases and after commissioning. Some sessions included other firms that were contracted to the project. Some lessons learned involved informal workshops. As one participant indicated, "There was a real push by our lessons learned manager to get $\log$ sheets out there for individuals to basically just put a one liner in there ... but it doesn't work as well as the facilitated sessions" (HT, p. 7). Safeguards and controls were in place to determine what meeting items were logged as official lessons learned to avoid "garbage-in-garbage-out" issues. Useful lessons learned were screened using criteria, risks/benefits and scalability to prioritize which investments needed to be pursued to improve practices by departments and/or the organization. Such analyses led to the identification of best practices, some of which were incorporated into standard operating procedures. Participants frequently discussed the use of a Project Management Office or a CoP to spearhead knowledge documentation and sharing.

Stakeholder involvement: Participants expressed frustrations related to getting contractors and partner firms to use their lessons learned databases. Some of the issues related to a lack of system integrations or lack of willingness to share lessons learned for reasons of trust, proprietary information and concerns over contractual obligations on the part of contractors. "It's lawyer driven and with the risk of, you know, litigation at some point in the future could be an absolute show stopper" (DN, p. 16).

Knowledge management and knowledge sharing practices: The storage and distribution of codified lessons learned involved databases, the intranet and electronic or study -based newsletters. Participants talked about the challenges related to staff compliance and the lack of user friendly systems. "I think it's easier to get stuff into the database but it can just become a black hole where getting stuff out is a whole other challenge" (DN, p. 8). Some participants discussed the importance of lessons learned as an investment in the company's knowledge capital. As one commented, "A lot of that involves tacit knowledge, sit down and talk one on one. What you read very often does not tell the whole story" (FD, p. 19). Others indicated that lessons learned were important because worker demographics were changing with retirements, turnover and younger lessexperienced employees being hired-all of which impacted institutional knowledge. The informal knowledge sharing practices confirmed the importance of tacit knowledge sharing and the value of social capital. However, this area warrants further study as we did not ask detailed questions for example, on how the participants made use of their social capital. 
Continuous improvement practices: Participants consistently identified the theme of continuous improvement in their descriptions of lessons learned. As one interviewee indicated, "So we don't continue to make the same mistakes over and over again. It's a continuous improvement exercise" (NZ, p. 2).

Management support: Reflecting company values, beliefs and norms, participants' descriptions of their company cultures indicated that the firms varied from being process-oriented to dynamic. Descriptions of their project management culture reflected practices that ranged from excellent to poor. Participants described project critical success factors as focusing on health/safety/environment, cost and scheduling. The ways in which lessons learned were supported by management, conducted and stored connoted embeddedness, a central theme that relates to ingraining knowledge capital within the company. "Well, the [lessons learned] are getting into the culture of the organization and holding the lessons learned sessions frequently enough, well that just becomes part of the way that we do business" (DN, p. 5). The practices used to embed lessons learned into the company fabrics reflected support for project management and continuous improvement practices. However, as one participant observed, "Although lessons learned focus on improvements, it still doesn't stop us from making some of the same mistakes over and over again" (FD, p 5).

A contribution of this study is that lessons learned practices are evolving. Additional focus is required on supporting the use of informal knowledge sharing practices (e.g., mentoring, role modeling and lunch-and-learn sessions). These practices represent intangible assets, which are sources of competitive advantage. Companies should explore various knowledge sharing practices and invest in such practices to robustly embed organizational knowledge. In light of significant over-runs on energy sector projects, we can make significant gains by focusing on lessons learned practices and recognizing their importance to project management and continuous improvement.

Following this exploratory study, we turned to the $\mathrm{PMBOK}^{\circledR}$ Guide to understand how it construes lessons learned.

Study 3: 2010-content analysis of the project management body of knowledge guide:

$\mathrm{PMI}^{\circledR}$ is the largest non-profit professional association for project managers. The association has over half a million members and advocates for the discipline through standards and certifications (PMI, 2010). The standards constitute the PMBOK ${ }^{\circledR}$ Guide. According to the guide, a project consists of five sequential yet overlapping process groups that span the lifecycle-initiation, planning, executing, closing and monitoring and control (which take place throughout the project) (PMI, 2010). These 5 process groups consist of 42 logical processes that span 9 standard knowledge areas:

- $\quad$ Project integration management

- Project scope management

- Project time management

- Project cost management

- Project quality management

- Project human resource management

- Project communications management

- Project risk management

- Project procurement management

Study 2: Materials and methods: We conducted a content analysis of the terms predominantly used in the PMBOK ${ }^{\circledR}$ Guide (Jugdev and Thompson, 2011). For the content analysis, we searched the 2008 edition of the guide for key terms. In doing so, we built on the aforementioned related literature reviews.

Study 2: Results: The $\mathrm{PMBOK}^{\circledR}$ Guide applies a systematic yet atheoretical (inputs-tools and techniques-outputs) model to each knowledge area using mechanistic and concrete language. The guide did not use the breadth of terms that we identified in our analysis of the literature nor conference proceedings as discussed earlier. Instead, the PMBOK $^{\circledR}$ Guide used its own vocabulary for lessons learned through such terms as audits, best practices, organizational process assets and lessons learned. Whereas the PMBOK $^{\circledR}$ Guide did not use the terms project evaluations, project audits, or post mortem health checks, it did use the term project reviews once (p. 310) in the context of project review meetings.

Audits: The $\mathrm{PMBOK}^{\circledR}$ Guide used the term audit eight times but did not define the term audit. Whereas the guide indicated that lessons learned are identified throughout the project, it used the term audit to refer to structured lessons learned activities/processes involving documentation. Although audits pertain to all the knowledge areas, the guide used the term in the context of only four of the nine knowledge areas (Integration Management, Quality Management, Risk Management and Procurement Management).

Best practices: Since lessons learned also pertain to applying best practices from prior projects onto future project phases and future projects, we included this term in our analysis. The PMBOK ${ }^{\circledR}$ Guide used the term best practices four times (PMI, 2010) but did not define the term. The term best practices were used in the context of the Time Management and Project Quality Management knowledge areas, yet they apply to all the knowledge areas. 
Organizational process assets: The $\mathrm{PMBOK}^{\circledR}$ Guide defined organizational process assets as "formal and informal plans, policies, procedures and guidelines [including]...knowledge bases such as lessons learned and historical information" (PMI, 2010). The guide labeled lessons learned as organizational knowledge bases along the line of tangible (concrete) databases involving documented historical information. Whereas the guide used the word process, it focused primarily on the asset dimension of lessons learned and it used the word process primarily in mechanistic ways (i.e., inputstools and techniques-outputs) versus a more organic and holistic approach as warranted for learning practices. Organizational process assets were addressed in the context of all the knowledge areas and referred to 227 times. Although the guide did not define the term organizational knowledge base, it did define a corporate knowledge base as a database.

Lessons learned: The PMBOK $^{\circledR}$ Guide referred to lessons learned 44 times (PMI, 2010). Lessons learned were documented only at the end of the project in the closing process group. Lessons learned were addressed in all nine knowledge areas. The guide consistently referred to lessons learned as activities or events, that is, knowledge bases, historical information and administrative documents and not processes. The guide referred to lessons learned in the context of codified materialinformation used to collect, distribute and archive project documents (e.g., templates, files, guidelines, records, policies, procedures, repositories). Additionally, the guide used an extremely mechanistic and rigid approach to learning, in how lessons learned are constructed.

The recommendations from this study were that practitioners should not accept the $\mathrm{PMBOK}^{\circledR}$ Guide at face value. The guide has value as just that, a systematic guide. However, it applies an atheoretical model to each knowledge area, including how it views lessons learned and related synonyms. The guide defines lessons learned narrowly, primarily as a set of administrative, documented outputs pertaining mainly to the closeout phase. This is also evident in the guide's commodification of lessons learned (and related terms) through its use of the term transfer to convey knowledge. The guide consistently refers to lessons learned as an activity involving outputs and not processes. The guide refers to lessons learned in a codified manner-information used to collect, distribute and archive project documents. Furthermore, although the guide espouses that lessons learned be done throughout the project lifecycle, the concept and related terms are not presented that way.

As of February 2012, the PMBOK ${ }^{\circledR}$ Guide was the fourth top selling book in the skills category within business and investing at Amazon. Com's best sellers list. PMI's ${ }^{\circledR}$ website indicated, "We serve practitioners and organizations with standards that describe good practices, globally recognized credentials that certify project management expertise and resources for professional development, networking and community" (PMI, 2010). Given $\mathrm{PMI}^{\circledR}$, s broad reach through its body of knowledge, various certification and practice standards, extensive professional development services and its research initiatives, we question why an influential association has adopted such a narrow approach to lessons learned.

In contrast to the PMBOK $^{\circledR}$ Guide interpretations, we view lessons learned to be more broadly defined as involving both activities and processes. It is incumbent on both researchers and practitioners to understand lessons learned as ways of mobilizing (constructing and sharing) valuable project knowledge in more than concrete ways (such as through meetings). The language used in the guide is very mechanistic and rigid when, in essence, lessons learned, learning and knowledge are more organic and fluid. Knowledge changes and it circulates. Knowledge goes beyond being transmitted or transferred.

Project management practitioners and scholars are encouraged to view the existing literature critically. They are urged to examine perspectives from workplace learning because these pertain to lessons learned, specifically situated learning theory. Finally, given $\mathrm{PMI}^{\circledR}$, s global reach, we should all question for ourselves and raise the matter with the association as to why it has adopted such a narrow approach to lessons learned.

\section{DISCUSSION}

The review of project management literature indicated that although lessons learned are important, the topic has yet to gain prominence. The literature review and two content analysis studies further found that there was a lack of consistency regarding the terms used for lessons learned. The content analysis of the PMBOK® Guide noted the narrow perspective that $\mathrm{PMI}{ }^{\circledR}$ takes in its interpretation and views on lessons learned. Whereas PMI® has a dominant place in industry and far reach through credentials, standards and professional development initiatives, its' portrayal of lessons learned is myopic. The guide presents lessons learned mechanistically and primarily as documented outputs (codified knowledge) pertaining mainly to the closeout phase. The guide commodifies lessons learned. Furthermore, the guide refers to lessons learned as an activity when it is also a process.

The qualitative study on lessons learned in the energy sector identified six key themes related to lessons learned that relate to success at the operational and organizational levels. The practices relevant to helping a company and related 
stakeholders achieve goals regarding success (Jugdev and Muller, 2005; Pinto and Slevin, 1987; 1988; Shenhar et al., 2001) are no different than what is required for lessons learned. This study supported the literature because not only are lessons learned evolving in their use in practice, but the overall emphasis continues to be on databases and codified information, as well as meetings to convey findings in the form of information. This finding was in stark contrast to the workplace learning literature that pertains to CoPs.

Although a stream of publications in project management has emerged on CoP, this stream addresses organizational learning and knowledge management theories in a cursory manner. Some publications anchored in the domain of informal knowledge sharing practices are emerging. The findings of our research program led to the proposition that the project management field has yet to expand research into the domain of workplace learning, which has significant merit for the discipline.

Based on these aforementioned studies and findings, our research program on lessons learned involves another study which is in progress (Jugdev and Mathur, 2012). Our 2010 study is a qualitative one with 15 experienced project management practitioners. The study questions focused on how knowledge was mobilized (shared), what learning's emerged from projects and how learning occurred in the project environment, how sharing was orchestrated and CoP practices. We are currently analyzing the transcripts and findings will be disseminated in 2012.

In this study, our contributions are at the theoretical, conceptual and practical levels. The current ways in which lessons learned are positioned in project management publications lacks a solid theoretical foundation. Without a solid theoretical foundation, concepts become harder to articulate, let alone measure and assess through empirical studies. This can hamper theory development and limit the extent to which others may want to anchor their research on project management studies on lessons learned. By introducing concepts on workplace learning theories to the field of project management, we attempt to stress the importance of bridging the two domains. Based on the broader and more robust conceptualizations of learning and sharing in the domain of workplace learning, especially situated learning theory, we posit that the field of project management would benefit by theorizing, conceptualizing lessons learned accordingly. We suggest that this will help develop a stronger theoretical foundation for research in project management on lessons learned.

Practically, our research program supports the view that a significantly broader interpretation of lessons learned may help organizations determine which practices to focus on. Lessons learned occur in formal, informal, self-directed, collective and social ways. Lessons learned are more than administrative, documented outputs (codified knowledge) pertaining mainly to the closeout phase. Lessons learned involve more than transferring knowledge from one person to study. Lessons learned are more than information used to collect, distributed and archive project documents (e.g., templates, files, guidelines, records, policies, procedures, repositories). Lessons learned are ways of mobilizing (constructing and sharing) valuable project knowledge. The processes of learning and sharing are organic and fluid and not mechanistic and rigid. We learn within and between our projects. Learning is also very participative and it involves teaching, learning and sharing in formal and less formal ways as discussed in this study. Knowledge is a social process and it is embedded in the practice, context and culture (Lave and Wenger, 1991). Knowledge changes and it circulates.

\section{CONCLUSION}

To conclude, the extant project management literature on lessons learned has helped advance our understanding of lessons learned by identifying best practices and barriers. However, our research program on lessons learned indicates that much work remains to be done. This study contributes to the fields of project management, knowledge management and workplace learning. We hope that this study serves to foster dialogue on the relevance of workplace learning to guide conceptual and empirical research.

\section{ACKNOWLEDGEMENT}

The researchers would like to acknowledge the generous support from Athabasca University, Alberta, Canada and funding support from the Social Sciences and Humanities Research Council of Canada. This study represents several collaborations with colleagues.

\section{REFERENCES}

Ahuvia, A.C., 2001. Traditional, interpretive and reception based content analyses: Improving the ability of content analysis to address issues of pragmatic and theoretical concern. Soc. Indic. Res., 54: 139-172. DOI: 10.1023/A:1011087813505

Bratton, J., J.C.H. Mills, T. Pyrch and P. Sawchuk, 2003. Workplace Learning: A Critical Introduction. 1st Edn., University of Toronto Press, Aurora, ON, ISBN: 1442601132, pp: 196.

Busby, J.S., 1999. An assessment of post-project reviews. Proj. Manage. J., 30: 23-29. 
Cameron, R., 2011. Mixed methods in business and management: A call to the 'first generation'. J. Manage. Organ., 17: 245-267.

Christensen, K.S. and H.K. Bang, 2003. Knowledge management in a project-oriented organization: Three perspectives. J. Knowl. Manage., 7: 116128. DOI: $10.1108 / 13673270310485686$

Crawford, L., J. Pollack and D. England, 2006. Uncovering the trends in project management: Journal emphases over the last 10 years. Int. J. Proj. Manage., 24: 175-184.

Currie, W.L., 2003. A knowledge-based risk assessment framework for evaluating webenabled application outsourcing projects. Int. J. Proj. Manage., 40: 207-217. DOI: 10.1016/s0263-7863(02)00095-9

Disterer, G., 2002. Management of project knowledge and experiences. J. Knowl. Manage., 6: 512-520. DOI: $10.1108 / 13673270210450450$

Duriau, V.J., R.K. Reger and M.D. Pfarrer, 2007. A content analysis of the content analysis literature in organization studies: Research themes, data sources and methodological refinements. Organ. Res. Method., 10: 15-34. DOI: $10.1177 / 1094428106289252$

Egbu, C.O., 2004. Managing knowledge and intellectual capital for improved organizational innovations in the construction industry: An examination of critical success factors. Eng. Constr. Archit. Manage, 11: 301-315. DOI: 10.1108/09699980410558494

Fenwick, T., 2008. Understanding relations of individual-collective learning in work: A review of research. Manage. Learn., 39: 227-243. DOI: $10.1177 / 1350507608090875$

Foss, N.J., 1996. Knowledge-based approaches to the theory of the firm: Some critical comments. Organ. Sci., 7: 470-476. DOI: 10.1287/orsc.7.5.470

Garrety, K., P.L. Robertson and R. Badham, 2004. Integrating communities of practice in technology development projects. Int. J. Proj. Manage., 22: 351-358. DOI: 10.1016/j.ijproman.2003.08.003

Gongla, P. and C.R. Rizzuto, 2001. Evolving communities of practice: IBM global services experience. IBM Syst. J., 40: 842-862. DOI: 10.1147/sj.404.0842

Hemetsberger, A. and C. Reinhardt, 2006. Learning and knowledge-building in open-source communities: A social-experiential approach. Manage. Learn., 37: 187-214. DOI: $10.1177 / 1350507606063442$

Jugdev, K. and R. Muller, 2005. A retrospective look at our evolving understanding of project success. IEEE Eng. Manage. Rev., 36: 19-31. DOI: 10.1109/EMR.2006.261387
Jugdev, K., 2006. Project lessons learned: Implications for an empirical study in the Canadian Energy Sector. Proceedings of the 1st International Construction Specialty Conference (ICSC-1), May 23-26, Towards a sustainable future, Calgary, Alberta, Canada.

Jugdev, K. and T.L. Thompson, 2011. A content analysis of the project management body of knowledge on lessons learned. Administrative Sciences Association of Canada, Montreal, QC.

Jugdev, K. and G. Mathur, 2012. Classifying project management resources by complexity and leverage. Int. J. Manage. Proj. Bus., 5: 105-124. DOI: $10.1108 / 17538371211192928$

Julian, J., 2008. How project management office leaders facilitate cross-project learning and continuous improvement. Proj. Manage. J., 39: 43-58. DOI: 10.1002/pmj.20071

Kamara, J.M., G. Augenbroe, C.J. Anumba and P.M. Carrillo, 2002. Knowledge management in the architecture, engineering and construction industry. Process, Manage., 2: 53-67. DOI: 10.1108/14714170210814685

Koners, U. and K. Goffin, 2007. Learning from postproject reviews: A cross-case analysis. J. Prod. Innov. Manage., 24: 242-258. DOI: 10.1111/j.1540-5885.2007.00248.x

Kotnour, T., 1999. A learning framework for project management. Proj. Manage. J., 30: 32-38.

Kransdorff, A., 1996. Viewpoint: Using the benefits of hindsight - the role of post-project analysis. Manage. Audit. J., 11: 42-46. DOI: 10.1108/02686909610120046

Kransdorff, A. and R. Williams, 1999. Swing doors and musical chairs. Bus. Horizons, 42: 27-32.

Lave, J. and E. Wenger, 1991. Situated Learning: Legitimate Peripheral Participation. 1st Edn., Cambridge University Press, Cambridge, ISBN: 0521423740, pp: 138.

Lesser, E.L. and J. Storck, 2001. Communities of practice and organizational performance. IBM Syst. J., 40: 831-841. DOI: 10.1147/sj.404.0831

Liebowitz, J. and I. Megbolugbe, 2003. A set of frameworks to aid the project manager in conceptualizing and implementing knowledge management initiatives. Int. J. Proj. Manage., 21: 189-198. DOI: 10.1016/s0263-7863(02)00093-5

Long, D., W. David and L. Fahey, 2000. Diagnosing cultural barriers to knowledge management. Acad. Manage. Exec., 14: 113-127. DOI: 10.5465/AME.2000.3979820

Newell, S., M. Bresnen, L. Edelman, H. Scarbrough and J. Swan, 2006. Sharing knowledge across projects: Limits to ICT-led project review practices. Manage. Learn., 37: 167-185. DOI: $10.1177 / 1350507606063441$ 
Nonaka, I. and H. Takeuchi, 1995. The KnowledgeCreating Company: How Japanese Companies Create the Dynamics of Innovation. 1st Edn., Oxford University Press, New York, ISBN: 0195092694, pp: 284.

O'Dell, C. and C.J. Grayson, 1998. If only we knew what we know: Identification and transfer of internal best practices. Calif. Manage. Rev., 40: 154-174.

Pettigrew, A.M., H. Thomas and R. Whittington, 2006. Handbook of Strategy and Management. 1st Edn., Sage Publications, London, ISBN: $141292121 X$, pp: 519.

Pinto, J.K. and D.P. Slevin, 1987. Critical factors in successful project implementation. IEEE Trans. Eng. Manage., EM34: 22-27.

Pinto, J.K. and D.P. Slevin, 1988. Critical success factors across the project life cycle. Proj. Manage. J., 19: 67-75.

PMI, 2010. A Guide to the Project Management Body of Knowledge(PMBOK Guide). 4th Edn., Project Management Institute, Newtown Square, PA., ISBN: 1933890665 , pp: 466.

Prusak, L. and D.J. Cohen, 2002. How to Invest in Social Capital (HBR OnPoint Enhanced Edition): Harvard Bus. Rev.

Schindler, M., 2003. Harvesting project knowledge: A review of project learning methods and success factors. Int. J. Proj. Manage., 21: 219228. DOI: 10.1016/S0263-7863(02)00096-0

Sense, J.A., 2003. Learning generators: Project teams re-conceptualized. Proj. Manage. J., 34: 4-12.

Sense, A.J., 2004. An architecture for learning in projects? J. Workpl. Learn., 16: 123-145. DOI: 10.1108/13665620410528498

Sense, A.J. and R.J. Badham, 2008. Cultivating situated learning within project management practice: A case study exploration of the dynamics of project-based learning. Int. J. Manag. Proj. Bus., 1: 432-438. DOI: $10.1108 / 17538370810883864$
Sense, A.J., 2008. Conceptions of learning and managing the flow of knowledge in the projectbased environment. Int. J. Manag. Proj. Bus., 1: 33-48. DOI: $10.1108 / 17538370810846405$

Shani, A.B. and P. Docherty, 2003. Learning by Design: Building Sustainable Organizations. 1st Edn., Blackwell Publishing, Malden, MA., ISBN: 063123277X, pp: 216.

Shenhar, A.J., D. Dvir, O. Levy and A.C. Maltz, 2001. Project success: A multidimensional strategic concept. Long Range Plann., 34: 699725. DOI: $10.1016 / \mathrm{S} 0024-6301(01) 00097-8$

Snider, K.F. and M.E. Nissen, 2003. Beyond the body of knowledge: A knowledge-flow approach to project management theory and practice. Proj. Manage. J., 34: 4-12.

Teece, D.J., 1998. Capturing value from knowledge assets: The new economy, markets for know-how and intangible assets. Calif. Manage. Rev., 40: 55-79.

Thompson, T.L. and K. Jugdev, 2010. Workplace learning theories and perspectives: Re-thinking project learning practices in administrative sciences association of Canada: Production and operations management track, Regina. SKA Dministrative Sciences Association of Canada, Regina, SK.

Wenger, E., 1999. Communities of Practice: Learning, Meaning and Identity. 1st Edn., Cambridge University Press, New York, ISBN: 0521663636, pp: 318.

Wilczynski, H., M. McKenna and D. VanderSchee, 2006. Unprecedented and unseen: The next great energy challenge. Strategy+Business. booz allen hamilton.

Williams, T., 2007. Post-Project Reviews to Gain Effective Lessons Learned. 1st Edn., Project Management Institute, Newtown Square, PA, ISBN: 193389024X, pp: 150.

Williams, T., 2008. How Do organizations learn lessons from projects-and do they? IEEE Trans. Eng. Manage, 55: 248-266. DOI: 10.1109/TEM.2007.912920 